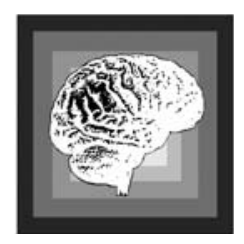

\title{
The Kraepelinian dichotomy: the twin pillars crumbling?
}

\author{
TALYA GREENE* \\ Institute of Psychiatry, King's College London
}

\begin{abstract}
Emil Kraepelin's view that psychotic disorders are naturally-occurring disease entities, and that dementia praecox and manic-depressive psychosis represent two different diseases, has been hugely influential on classificatory systems for psychosis. Corresponding to the Kraepelinian dichotomy, those systems generally differentiated schizophrenia from affective psychosis. This paper examines the debate that took place between 1980 and 2000 regarding this differentiation. During the 1980s, the scientific reliability of the diagnostic criteria was challenged. In the 1990s there were significant critiques of the validity of the Kraepelinian dichotomy. Yet the dichotomy has not been formally abandoned, and the discussion continues to the present day. This paper suggests that before psychiatry can abandon the Kraepelinian dichotomy, a new model for conceptualizing and describing psychotic symptoms may be required.
\end{abstract}

Keywords: affective disorder; classification; Emil Kraepelin; Kraepelinian psychiatry; psychosis; schizophrenia; 20th century

\section{Introduction}

Emil Kraepelin's view that psychotic disorders could be conceptualized as naturally-occurring disease entities which could largely be differentiated into dementia praecox and manic-depressive psychosis, has had a huge impact on twentieth-century psychiatry. The rise of neo-Kraepelinian psychiatry in the 1960 s and 1970 s contributed to the construction of DSM-III, in which the Kraepelinian dichotomy between schizophrenia and psychotic affective disorders became embedded in psychiatric classification. Nevertheless, there have been repeated challenges to the Kraepelinian conceptual framework

\footnotetext{
* Address for correspondence: Institute of Psychiatry, King's College London, Department of Psychological Medicine, Weston Education Centre, 10 Cutcombe Road, London, SE5 9RJ, UK. Email: talya10@hotmail.com
} 
throughout the twentieth century. This paper examines the debate that took place from the publication of DSM-III in 1980 to the end of the twentieth century regarding the Kraepelinian division of schizophrenia and psychotic affective disorders.

\section{Background}

At the turn of the twentieth century, Kraepelin proposed that psychotic mental disorders could be understood as expressions of real biological illnesses. In 1883 he published his 385-page textbook of psychiatry (Kraepelin, 1883). Drawing on the traditions of nineteenth-century science, Kraepelin developed a nosological system of classification for serious mental illnesses which were published in nine successive editions of his textbook. By the final edition (Kraepelin and Lange, 1927), it had grown to a two-volume publication with 2425 pages. Throughout these years, Kraepelin maintained that mental illness consisted of a finite number of natural disease units, each with its own distinct pattern of symptoms, aetiology and anatomy. Kraepelin argued that 'aspects' or symptoms carried information as to the 'essence' of disease, and that symptomatology, therefore, could provide a means for classifying disease.

In the sixth edition of Psychiatrie published in 1899, Kraepelin presented catatonia and dementia paranoides together with hebephrenia as forms of dementia praecox (Kraepelin, 1902). (The Swiss psychiatrist, Eugen Bleuler, would later rename dementia praecox as schizophrenia; Bleuler, 1911/1950.) In this edition, Kraepelin clearly proposed the separation of dementia praecox from manic-depressive psychosis (now referred to as bipolar disorder). $\mathrm{He}$ asserted the dementia praecox was caused by 'a definite disease process in the brain' (Kraepelin, 1902: 153). He claimed that 'in a few cases this is a reparable lesion, but in most cases the impairment of function is permanent and progressive' (p. 283). In manic-depressive illness, however, the main aetiological factor was considered to be defective heredity. Manic-depressive illness was also seen to have a better prognosis than dementia praecox.

Towards the end of his career, Kraepelin began to have some doubts about his system. In 1920 he published an article on 'The Manifestations of Insanity' in which he argued that psychiatric illness could be understood as groups of symptoms generated by underlying patterns of brain activity (Kraepelin, 1992[1920]). He claimed that 'we naturally will then turn our attention from merely classifying and categorizing diseases to a more exalted and satisfying exercise - understanding disease processes and how they inter-relate' (p. 509). He abandoned the view that psychotic symptoms were specific to a particular pathology. He argued:

The learnt mental mechanisms which give rise to these manifestations of disease are not confined to a particular disease process, but can be evoked 
in the same form by a variety of morbid insults ... we must be very wary of claiming that a particular disorder is characteristic of one and only one particular disease process. (p. 518)

Although he had previously argued for the differentiation of manic-depressive insanity from dementia praecox, Kraepelin ultimately concluded: 'we cannot satisfactorily distinguish between these two diseases. The suspicion remains that we are asking the wrong questions' (p. 527).

Despite Kraepelin's concerns in 1920 about his theories, in the eighth edition of Psychiatrie he maintained that 'the proof is furnished that our picture is in the main agreeable to natural law' (Kraepelin, 1919/1971:252). Even in the 1920 article in which he discussed the difficulties in adequately distinguishing between dementia praecox and manic-depressive illness, he still argued that 'the two disease processes themselves are distinct' (Kraepelin, 1992 [1920]: 527). He concluded that 'this distinction is too overwhelming for us to accept much overlap between the two groups, particularly as we can often predict the course of the two from the clinical signs' (p. 528). Ultimately, he said, 'we must at all costs adhere to the basic difference between the disease processes concerned' (p. 528).

Thomas Kuhn (1962) argued that science works within paradigms, or schools of thought, that shape research questions, methodologies and concepts. Kraepelin's nosological system was hugely influential throughout the last two decades of the twentieth century, particularly with regard to the separation between schizophrenia and affective psychoses, so much so that the Kraepelinian model became the central paradigm for psychiatry (Ion and Beer, 2002; Jablensky, 1995; Van Bakel, 1993). As J. P. Gueguen (1988/1997: 2) writes, Kraepelin, 'through a rigorous clinical approach, found[ed] all the great nosological frames, which even today provide a reference for us'. Similarly, Tim Crow (1990: 790) points out that the Kraepelinian dichotomy:

has fared so well that no respectable textbook is without separate chapters on the two 'diseases' and much of the impetus behind modern operation diagnostic criteria (DSM-III and so forth) is directed at distinguishing these supposed entities with maximum reliability.

Despite the apparent dominance of the Kraepelinian system, there are many historians and mental health clinicians who now challenge it, questioning whether the paradigm is a 'true' system that corresponds to real disease entities. Berrios, Luque and Villagrán (2003) argue that a 'continuity myth' has been constructed. According to the myth, schizophrenia has always existed, was discovered by Kraepelin, and since then psychiatrists have been improving and refining concepts and knowledge of it. This approach implies that it is only a matter of time before the genetics and aetiology of schizophrenia are understood. Berrios et al. (2003: 115) go so far as to state 
that this 'myth ... is almost beyond the reach of empirical correction or falsification'.

In 1952 the Diagnostic and Statistical Manual of Mental Disorders (later, $D S M-I$ ) was published by the American Psychiatric Association (APA, 1952). A number of different psychiatric diagnostic manuals had previously been published, mainly for use in mental hospitals, and DSM-I represented an attempt to standardize diagnoses (Compton and Guze, 1995). In DSM-I, most disorders were referred to as 'reactions' precipitated by environmental events. All people were considered to react to their environment to a certain extent, and mental disorders were therefore seen as a question of degree rather than of kind. In $1968 D S M-I I$ was published (APA, 1968). The stated aim of this second edition was to facilitate 'maximum communication within the profession and reduce confusion and ambiguity to a minimum'(APA, 1968: viii). This version was heavily influenced by psychoanalysis, which was then at its peak in the USA. Most conditions were referred to as neuroses rather than as reactions. The descriptions were brief and did not contain much indication of the clinical criteria required for diagnosis.

By this time, the anti-psychiatry movement of the 1960s and early $1970 \mathrm{~s}$ had begun to challenge the Kraepelinian basis for concepts of psychosis. Ronald D. Laing, a Scottish psychiatrist, made a radical break from the accepted norm by claiming that schizophrenia was not a disease in the classic sense as it had no anatomical or biochemical lesion. Rather, schizophrenia was a reaction to a hopeless situation, in which the individual 'chooses' the symptoms as an exit from intolerable pain (Laing, 1960). Laing (1960: 7) argued that psychiatric disorders were not 'medical illness but a diagnostic designation, arbitrarily fixed by society and confirmed by psychiatrists'. Similarly, the US psychiatrist, Thomas Szasz, developed a notion of the uselessness of psychiatry as a discipline. "“Mental illness" is a metaphor', Szasz wrote, 'strictly speaking, disease or illness can affect only the body; hence, there can be no mental illness.' Moreover, he claimed that 'psychiatric diagnoses are stigmatizing labels, phrased to resemble medical diagnoses and applied to persons whose behaviour annoys or offends others' (Szasz, 1974: 267).

In 1973 a US sociologist, David Rosenhan, conducted a study in which he enlisted seven 'normal' associates and instructed them to present themselves to doctors complaining that they were hearing a voice saying 'thud', 'empty' or 'hollow' (Rosenhan, 1973). Beyond the alleged symptoms and the falsification of names and occupations, the confederates were to act completely normally, and present their life histories as they had actually occurred. The confederates were all given a diagnosis of schizophrenia and committed to psychiatric hospitals. Despite displaying normal behaviour, the pseudo-patients remained hospitalized for 9-52 days, with an average stay of 19 days. At no time during their hospitalization was the legitimacy of their schizophrenia diagnosis called into question. Rosenhan concluded that mental health professionals 
were unable to distinguish effectively between the sane and insane. This influential study challenged both the reliability of the diagnostic criteria for schizophrenia, and the power attached to psychiatric labels.

In response to such attacks on psychiatric classification, a movement developed that reaffirmed the Kraepelinian approach to diagnosis and classification (Blashfield, 1984). Gerald L. Klerman (1978: 104) conceptualized this school of thought as 'neo-Kraepelinian'. The neo-Kraepelinian approach took psychiatry to be a branch of medicine that should use modern scientific methodologies. Neo-Kraepelinians viewed people with mental illnesses as sick and clearly distinct from healthy people. They asserted that mental illnesses were real pathobiological entities, and that scientific psychiatry should investigate the causes, diagnosis and treatment of these mental illnesses, with a particular emphasis on the codification of diagnostic criteria (Klerman, 1978).

The neo-Kraeplinians, although not connected in any official way, worked together to promote their approach. Blashfield (1982) described this informal network with their common beliefs, methodologies and research interests as an 'invisible college': there was a tendency among this group to produce papers which actively reinforced one another's findings. Blashfield gives as an example a key neo-Kraepelinian paper: 'Diagnostic criteria for use in psychiatric research' published in Archives of General Psychiatry by Feighner, Robins, Guze, Woodruff, Winokur and Munoz (1972), which codified neo-Kraepelinian psychiatric diagnostic criteria. Blashfield found that this was cited more than 79 times as often as the average paper published in this journal; he concluded that this was due to the invisible 'college effect' of the neo-Kraepelinian group promoting the Feighner et al. paper by writing many articles that cited it.

The impact of this group could be seen in the third edition of the DSM, published in 1980. Robert Spitzer, a prominent neo-Kraepelinian and the chair of the DSM-III Task Force, was concerned that the challenges over the reliability of psychiatric diagnoses could invalidate the whole of psychiatry (Spitzer and Fleiss, 1974). Spitzer attempted to address this concern in DSM-III by creating precise diagnostic criteria. DSM-III maintained the distinction between schizophrenia and affective psychotic disorders; an absence of affective symptomatology was listed amongst the criteria for a schizophrenia diagnosis. The influence of the neo-Kraepelinian movement could be seen in its use of more exacting and operationalized criteria with descriptions of symptoms, aetiology, familial pattern and differential diagnosis, and in the perception of a clear divide between normal and abnormal.

Many psychiatrists saw DSM-III as demonstrating a fundamental or revolutionary change in the approach of psychiatry, moving from psychodynamic theories to an emphasis on science and biology (Andreasen, 1985; Maxmen, 1985). Maxmen (1985: 35) stated that 'the ascendance of scientific psychiatry became official' by the adoption of DSM-III', and he asserted: 
'The old psychiatry derives from theory, the new psychiatry from fact' (p. 31). However, in many ways, DSM-III was a reassertion of Kraepelin's concepts, rather than a revolutionary new approach (Ghaemi, 2003).

The approach characterized by DSM-III could be seen in the work of many psychiatrists in the early 1980s. For example, Irving I. Gottesman and James Shields (1982) published an influential book, Schizophrenia: The Epigenetic Puzzle, which was constructed around the assumption that schizophrenia is a real disease, with a genetic basis, and that further research would reveal its nature in full. The authors optimistically and incorrectly declared that 'the schizophrenia puzzle is in the process of being solved before the twentieth century ends' (Gottesman and Shields, 1982: 235). They used a combination of family, twin and adoption studies to lay the foundations for their claims that schizophrenia has a genetic component and is a discrete disease entity. They considered schizophrenia to be comparable to diseases such as diabetes and heart disease, in which only predisposed individuals develop the illness, with environmental factors increasing the risk. A number of other researchers conducted family and twin studies and similarly concluded that there was a genetic basis to schizophrenia and affective disorders, and that the two disorders were independent of each other (Gershon and Rieder, 1980; Loranger, 1981; Reich, Cloninger, Suarez and Rice, 1982).

\section{Challenges to the Kraepelinian dichotomy}

Despite the claims that DSM-III had brought a revolution in psychiatry, the concepts proposed in it immediately came under scrutiny. While the antipsychiatrists of the 1960s rejected psychiatric concepts and labels on social and political grounds, this next wave of critics looked to empirical evidence to make their case. They placed themselves firmly within the scientific community, arguing that the concepts formulated about schizophrenia and manic depression were arbitrary classificatory categories, without scientific reliability or validity. Debate during the 1980 s centred around the diagnostic criteria for schizophrenia. Particular points of contention were whether schizophrenia could be reliably separated from other psychiatric disorders and whether schizophrenia represented one heterogeneous disease, or whether it was made up of a number of more homogenous diseases.

Robert E. Kendell and Ian Brockington (1980: 326) claimed that Kraepelin's concepts of dementia praecox and manic-depressive insanity became 'the twin pillars on which our classifications have been based'. However, they criticized this conceptualization, arguing that if diagnostic categories were to be considered genuine disease entities, 'it should imply a natural boundary or discontinuity' between disorders, and it should be possible to identify this break or, as they termed it, a 'point of rarity' (p. 324; original italics). However, they failed to demonstrate a discontinuity between 
schizophrenia and the affective psychoses. This led them to conclude that a point of rarity may not exist.

In response, Cloninger, Martin, Guze and Clayton (1985) conducted a study in which they mounted a defence of the Kraepelinian dichotomy and attempted to show a discontinuity between psychotic disorders. They used narrower criteria to define the disorders and claimed to have demonstrated a bimodal distribution of psychosis. They concluded that 'there is a natural boundary, or point of rarity, in the symptoms that distinguish schizophrenics from other persons, including both normal subjects and patients with other psychotic and nonpsychotic disorders' (Cloninger et al., 1985: 22). However, this paper stood alone as the only study in which a point of rarity was demonstrated.

According to the Kraepelinian model, if the two disorders were disease entities, with a genetic basis, one would expect to see an increased propensity for schizophrenia in the family members of schizophrenia patients, and an increased propensity for bipolar disorder among family members of those diagnosed with bipolar disorder. Theoretically, if the two disorders were unrelated, there would be no increased likelihood of finding bipolar disorder in the family members of schizophrenic patients and vice versa. Furthermore, it would be expected that monozygotic twin pairs would receive the same diagnosis as each other. However, a number of family studies did not seem consistent with the Kraepelinian model, and instead seemed to support Kendell's position that there was no clear boundary between the two disorders. One study described identical male triplets, two of whom were diagnosed with schizophrenia and one with bipolar disorder (McGuffin, Reveley and Holland, 1982). Another described identical twins, one who had been diagnosed with schizophrenia and the other with bipolar disorder (Dalby, Morgan and Lee, 1986). A key family study showed that relatives of schizophrenia patients had an increased likelihood of being diagnosed with bipolar disorder (Kendler, Gruenberg and Tsuang, 1985). These studies undermined the case that affective disorders and schizophrenia were discrete disease entities with distinct genetic causes (Stassen, Scharfetter, Winokur and Angst, 1988: 115).

Another important study was published in 1987 by Farmer, McGuffin and Gottesman. They looked at identical twin pairs and found that out of 27 pairs with one member diagnosed with schizophrenia, six had a pair concordant for schizophrenia, but seven had a pair diagnosed with a mood disorder. Farmer et al. (1987: 634) noted that 'it may be questioned whether it is the genetic control of schizophrenia or the validity of the operational definition that is being tested'. They continued, 'it is apparent that DSM-III has not necessarily achieved an optimal placement of the boundaries of schizophrenia, since uncomfortable anomalies have arisen concerning the diagnostic discordance of certain twin pairs' (p. 640). This is a particularly interesting study because while these 'uncomfortable anomalies' could be 
interpreted as suggesting a connection between schizophrenia and affective disorder, these researchers preferred to argue that the results were due to problems with the DSM-III criteria. This shows the extent to which the Kraepelinian dichotomy was framing the interpretation of results.

Other researchers, however, were calling into question the sharp distinction between the two disorders. Crow recognized that there was a correlation between the type of psychosis seen in a patient and in their family members, declaring that 'without this, the Kraepelinian dichotomy could hardly have survived' (Crow, 1986: 424). However, he also argued that the existence of cases of psychosis with mixed manic affective and schizophrenic symptoms was problematic for the dichotomy. Therefore, he concluded that the 'affective psychoses and schizophrenia are related to each other on a continuum and that this continuum has a genetic basis' (p. 426). Others came to similar conclusions, continuing to see distinctions between mixed manic affective and schizophrenic symptoms, but also recognizing graduations and overlaps between the two (Angst, Scharfetter and Stassen, 1983; Gershon et al., 1988; Kety, 1985).

Kendell (1987) claimed that the main problem was that the aetiology of psychotic disorders was not understood, therefore clinicians and researchers used the symptomatology to differentiate between psychotic disorders. However, the significant degree of overlap between the symptomatology caused problems. Kendell (1987: 511) wrote, 'not one of them [psychotic disorders] is yet demarcated by its neighbours by clear boundaries. All are still defined by their clinical syndromes, and these syndromes merge imperceptibly into one another'.

In 1987 the revised edition of DSM-III was published (DSM-III-R) in an attempt to address the problems of reliability in using the criteria to reach a diagnosis. In the introduction to DSM-III-R, Spitzer and Williams (1987: xvii) wrote:

Despite extensive field testing of the DSM-III criteria before their official adoption, experience with them since their publication had revealed, as expected, many instances in which the criteria were not entirely clear, were inconsistent across categories, or were even contradictory.

However, the revised edition did not address the issue of the validity of the diagnostic categories, and this remained problematic.

Many took issue with what they saw to be arbitrary categories. Ciompi (1984: 636) ironically declared that 'it seems obvious that there is a schizophrenia, since our psychiatric institutions are filled with patients with this diagnosis'. Richard Bentall, a British clinical psychologist, and colleagues concluded that "schizophrenia" is not a useful scientific category and that for all these years researchers have been pursuing a ghost within the body of psychiatry' (Bentall, Jackson and Pilgrim, 1988a: 318). Yet despite criticizing the arbitrary nature of the classifications, most of these critics acknowledged 
the utility of diagnostic classifications. For example, William N. Goldstein, a psychodynamic-based psychiatrist argued that although DSM-III presented a reliable and straightforward method for making diagnoses and to structure research, this does not necessarily mean it is a true or good system (Goldstein, 1983). Goldstein concluded:

DSM-III provides diagnostic criteria that are simply arbitrary. There is no reason to think that DSM-III is inherently better than DSM-I, DSM-II, Bleuler, or many other diagnostic systems. DSM-III should be accepted only as one system, among many, for making the diagnosis of schizophrenia ... At the present time, when evaluating a patient for schizophrenia, DSM-III should be considered, but clearly not as the final word. (p. 179)

While a psychodynamic psychiatrist publishing in the American fournal of Psychotherapy might be expected to criticize the psychiatric approach, Brockington, a more traditional psychiatrist, expressed a similar sentiment. Writing in 1986, he agreed that 'schizophrenia' was just a classificatory notion, grouping together patients who shared some symptoms and had a similar illness-course (Brockington, 1986).

Robin M. Murray and Alice Foerster (1987) similarly argued that schizophrenia is useful as a provisional category, but that it may be abandoned in the future as the mechanisms of psychosis become better understood. While they acknowledged that the concept of schizophrenia could be mistaken, they still supported 'Kraepelin's view that both heredity and brain disorder are implicated [in psychosis]' (p. 138). Therefore, they suggested: 'perhaps in the near future we will be able to take our stance on the subdivision of psychosis according to aetiological principles rather than on the quicksands of symptomatology and course' (p. 138).

Although many criticized the Kraepelinian dichotomy, they suggested no alternative, and were forced to accept its utility in providing a common language for psychiatry and in shaping research and treatment. As Kendell (1987: 500) wrote:

The structure remains unchanged not because the rubrics concerned have been shown to represent valid and independent entities, but because no better classification has yet been devised, and because we are aware that if the twin pillars of manic-depressive psychosis and schizophrenia are disturbed before there is anything better to put in their place the roof will come crashing in.

The 1980 s can be seen as the decade when a new kind of scientific-based criticism to the Kraepelian model was introduced. This may have been partly due to the establishment of the more 'scientific' DSM-III model with which to disagree. That is to say that the concepts in themselves set up a situation where the criticism of them, in order to be effective, needed to be 
based on scientific grounds. Unlike much of the research quoted here, most of the literature discussing problems with the schizophrenia criteria during the 1980s failed to mention the difficulties in separating it from bipolar disorder. Part of the reason for this may be the relative discrepancy between the volume of research on schizophrenia and bipolar disorder, with relatively little focus on bipolar disorder and its aetiology and symptomatology. This may have limited potential for understanding any similarities between the two disorders. Secondly, the dominant assumption that there were discrete disorders prevented many people from considering other models of psychosis seriously. Despite all the challenges to the dichotomy, Berrios and Hauser could still maintain in 1988 that it was a 'fact' that 'current psychiatry lives in a Kraepelinian world' (Berrios and Hauser, 1988: 813).

\section{The 1990s: critiques and alternative approaches}

By the 1990s, while there was still a sense that concepts such as schizophrenia provided an 'anchor from which developments can take place' (Venables, 1990: 203-4), criticisms of the dichotomy were growing, particularly regarding the reliability of the diagnostic categories. Kendell remained a key critic of the system into the 1990s. He declared in 1991:

For the last 20 years I have been dismayed by the widespread assumption that schizophrenia and manic-depressive illness are distinct diseases simply because we have given them different names ... I have therefore tried again and again to convince my students and colleagues that these assumptions are unjustified and that we must be prepared to consider other possibilities. (Kendell, 1991: 13)

Kendell concluded that it might be that the Kraepelinian assumptions would turn out to be correct, and indeed that he would be pleased if they did. However, he asserted, there was not enough evidence to convince him that this was the correct conceptualization of psychosis (Kendell, 1991). Although criticisms of the reliability of the diagnostic criteria for psychosis lessened during the 1990s, criticisms of the validity of the Kraepelinian dichotomy gathered force. A number of alternative approaches were proposed, building on a broad range of evidence.

Bentall has been one of the strongest advocates for abandoning the Kraepelinian dichotomy. Together with a number of other critics such as Mary Boyle and Theodore Sarbin, he put forward cases against schizophrenia (Bentall, 1990; Boyle, 1990; Sarbin, 1990). They subjected schizophrenia to scientific and historical scrutiny and argued that the concept of schizophrenia lacked scientific reliability and validity and thus should not form the framework for thinking about psychosis. Bentall edited a key volume in this debate entitled Reconstructing Schizophrenia (Bentall, 1990). In the preface he wrote that his intention was to reconsider the concept of schizophrenia afresh. 
He argued that although the anti-psychiatrists of the 1960s and early 1970s claimed to be doing just this, their criticisms failed because they were based on poor and contradictory evidence (p. xiv). Bentall asserted:

Some [critics] appeared to be rejecting scientific method or their ideas failed to convince many people working in the domain of mental health ... This has led to the illusion that one is required to take one of two possible positions: either to accept the traditional account of psychiatric disorder (together with the forms of crude biological reductionism that inform it) or to reject an empirical approach to understanding madness altogether (throwing scientific reasoning out with the psychiatric bathwater in the process).

By explicitly differentiating himself from the much criticized anti-psychiatrists who rejected empirical methods, Bentall sought from the outset to place himself within the scientific community (Bentall, Jackson and Pilgrim, 1988b: 330). He proposed that schizophrenia is a hypothetical construct, and that psychosis would be better understood and treated by studying the specific symptoms of madness (Bentall, 1990). He claimed:

Serious questions remain about whether schizophrenia can be considered an illness; about whether it is one condition or several, about whether clear dividing lines can be found between schizophrenia and normal function or even between schizophrenia and other kinds of mental disorder. (Bentall, 1990: xiii)

Similarly, Boyle, a clinical psychologist, rejected the schizophrenia concept on what she claimed were scientific grounds. She maintained that 'the concept of schizophrenia ... has been developed and used in a way which bears little resemblance to the methods of construct formation used in medical and other empirical sciences' (Boyle, 1990: 193).

Charles G. Costello (1993a) argued that although it is important to investigate syndromes of schizophrenia, he agreed with Bentall that it may be more effective and advantageous to investigate specific symptoms. Nevertheless, Costello (1993b) asserted that while the symptom approach may be more fruitful than focusing on diagnostic categories, symptoms should not be considered in isolation, but rather in relation to all the other symptoms. He claimed that this symptom approach may eventually give rise to an understanding of typical symptom clusters that are the 'syndromes of schizophrenia' (Costello, 1993b: 300).

Reviewing the family and genetic studies from the 1980s, Crow (1991:31) thought that the assumption that schizophrenia and bipolar disorder represent two distinct disease entities 'has been paralytic to our thinking and stultifying to research'. He rejected much of the evidence from family studies, arguing that the sample groups only included those who met the standardized criteria for bipolar disorder or schizophrenia and excluded schizoaffective 
cases, and therefore a conclusion that there is little overlap was more likely (Crow, 1991). Instead, drawing on the studies, discussed above, which suggested that psychosis was likely to have a genetic basis and that there was an overlap between schizophrenia and bipolar disorder, Crow suggested that both disorders were affected by the same psychosis gene. He moved the discussion forward by claiming that there is an increased likelihood of psychotic patients within the same family being of the same sex and therefore proposed that the psychosis gene is located on the sex chromosome.

Recent developments in genetic research have also given support to this position. For example, overlapping genetic linkage regions for schizophrenia and affective disorders have been found (Wildenauer, Schwab, Maier and Detera-Wadleigh, 1999). The authors argued that these overlaps suggest that a number of common genes may be involved in both these categories. On that basis, they concluded that the Kraepelinian dichotomy requires re-evaluation.

Murray and O'Callaghan (1991) agreed with Crow that the distinction between schizophrenia and psychotic affective disorder is flawed, but they rejected Crow's explanations. Rather, they argued that the dividing lines between the disorders have been incorrectly drawn and that there are several different aetiological factors that affect the functional psychoses. Murray and O'Callaghan proposed dividing psychosis into congenital psychoses, which they considered to have resulted from abnormalities present at birth, and other psychoses that only arise during adulthood. They triumphantly asserted that they found 'no support for the current "Kraepelinian" distinction between manic-depression and schizophrenia' (Murray and O'Callaghan, 1991: 60) and that 'the pillars supporting the Kraepelinian dichotomy of the functional psychoses are crumbling' (Murray, O'Callaghan, Castle and Lewis, 1992: 326). But while they rejected the received view of the Kraepelinian dichotomy, they seemed unwilling to reject Kraepelinian ideas absolutely, claiming that 'the congenital psychoses closely resemble Kraepelin's original description of dementia praecox' (Murray and O'Callaghan, 1991: 60).

Other researchers proposed new ways of understanding the dichotomy. Cloninger (1994) rejected both the discrete dichotomy model, and Crow's severity continuum model, arguing rather that schizophrenia and bipolar disorder should be considered as two discrete disease spectra which show some overlap at their extreme ends. Van Os, Jones, Sham, Bebbington and Murray (1998) argued that the studies on risk factors for psychosis suggest that there may be evidence for quantitative differences between schizophrenia and affective psychosis, but not for qualitative differences. They proposed:

A psychopathological continuum, with discrete effects working preferentially, though not exclusively, at particular ends of the continuum. 
We suggest that there is a gradient both in terms of severity/prognosis and the magnitude of the effect of the risk factors, along dimensions of the continuum, rather than qualitative distinctions between categories. ( $p$. 602 ; original italics).

Van Os et al. concluded that 'it may be time to pay more than lip service to the idea of a psychotic continuum, and to conceptually incorporate the notion in the way the search for the determinants, complications and treatments for psychosis is conducted' (p. 603).

Andreasen (1997: 108) conceptualized this interest in the full range of psychotic symptoms as 'coming back full circle' to the past work of people like Kraepelin himself, among others. It seems as if, like Murray and O'Callaghan (1991), Andreasen was reluctant to distance herself entirely from Kraepelinian ideas.

In $1994 D S M-I V$ was published (APA, 1994). It was based on a systematic review of the available scientific knowledge of psychiatric disorders, and was thus considered more empirical. However, McCarthy and Gerring (1994) examined the DSM-IV construction process and concluded that the revision functioned more as an attempt to give theoretical and scientific credibility to the biomedical model of psychiatry, rather than as a fundamental reconceptualization of mental disorders.

There still seemed many questions over the validity of the entities described in $D S M-I V$. Although in the preface it was claimed: 'there is no assumption that each category of mental disorder is a complete discrete entity with absolute boundaries dividing it from other mental disorders or from no mental disorder' (APA, 1994: xxii), it was later (p. 283) stated that 'much evidence suggests the importance of genetic factors in the aetiology of schizophrenia', demonstrating that it maintained the concept of schizophrenia as representing a natural disease entity.

By the end of the twentieth century, psychiatrists had generally come to agree that although the problems of reliability were addressed by $D S M-I V$, the validity of the diagnostic categories for psychosis was still problematic (Craddock and Owen, 2005; Van Os et al., 1999). Ovsiew went so far as to say that, 'clinging to the idea, outmoded by biological data, that the classic clinical pictures represent distinct disease entities has been and continues to be a brake on progress.' The new challenge, he stated, 'is to devise diagnostic dimensions that have heuristic value for neuroscientific research and that can also guide clinical understanding and intervention' (Ovsiew, 2000: 298).

\section{Retreating but not surrendering}

Yet, despite the agreement that the dichotomy is flawed, it still exists in the official diagnostic systems. In 1995, European Archives of Psychiatry and Clinical Neurosciences published a special issue on the impact of Emil 
Kraepelin's concepts on world psychiatry. Jablensky, the guest editor of this issue, asserted that 'as clinicians and researchers, we today continue to operate in a Kraepelinian paradigm which started emerging nearly a century ago' (Jablensky, 1995: 186).

Kraepelin's ideas have remained influential, not because they are demonstrably 'true', but because they became paradigmatic within the field of psychiatry. Psychiatric textbooks, official diagnostic systems, psychiatric investigations and clinical treatments are still organized in a way that reflected Kraepelinian assumptions about mental disorders (Bentall, 2003). The Kraepelinian dichotomy has retained its attraction for clinicians, because, as Craddock and Owen (2005: 364) write, it is 'conceptually simple and allows psychiatrists to demonstrate diagnostic expertise by exercising judgement over an often complex clinical picture and to reach a clear diagnosis'.

The dichotomy may also have been maintained because, even if potentially flawed and 'in the absence of fully informed causal mechanisms' (Compton and Guze, 1995: 197), many have perceived it as an aid to research and treatment of psychosis. As Craddock and Owen (2005: 364-5) point out:

Kraepelinian diagnoses formed the basis of recent successes in genetics, probably because their net effect is to simplify the genetic architecture of the groups defined, albeit at the expense of excluding many cases. The dichotomy also formed the basis of the operational diagnostic criteria that brought a degree of rigour and reproducibility to psychiatric research.

Compton and Guze (1995) note that the separation of manic-depressive psychosis from dementia praecox, enabled developments such as the specific treatment of bipolar disorder with lithium, and other antimanic agents. Also, despite many studies that have shown that the data do not fit the traditional dichotomy, the proponents of the alternative approaches have not yet accumulated enough evidence to demonstrate that their method is better (Craddock and Owen, 2005).

Kuhn (1962) argued that within any paradigm, anomalies will arise that cannot be explained. Generally anomalies are ignored or are explained as experimental errors. However, some anomalies are considered too significant to ignore, and they push the paradigm into a state of crisis. Eventually a new paradigm emerges that deals with the anomalies, and this causes a paradigm shift. By the end of the twentieth century it was clear that there were significant anomalies within the Kraepelinian paradigm, but it did not seem that psychiatry was in a state of crisis.

Part of the difficulty with moving on from the Kraepelinian dichotomy is that it is difficult to understand how it might be done. This is partly due to the practical difficulties of actually applying these concepts in a clinical setting (Craddock and Owen, 2005). In Kuhnian terms, it may be that the 
lack of a viable alternative paradigm is a limiting factor in abandoning the Kraepelinian dichotomy. Psychotic symptoms are real phenomena, and clinicians need some kind of framework to conceptualize, investigate and treat these symptoms. As Hugh Freeman (2003: 32) concluded, 'mental health professionals must continue to practise the art of the possible ... To abandon Kraepelin may also be to lose sight of clinical understanding.'

\section{Conclusion}

From the late 1970 s, the neo-Kraepelinians actively reconstructed psychiatry around scientific and medical assumptions in order to fight off criticisms. The impact of the 'invisible college' of neo-Kraepelinians could be seen with the creation of DSM-III that contributed to the entrenchment of the Kraepelinian paradigm. With the construction of DSM-IV, this paradigm was firmly consolidated. During the 1980s these 'scientific' concepts met with a scientific criticism that challenged the Kraepelinian dichotomy, particularly regarding questions of the reliability of the diagnostic criteria in distinguishing between the two disorders. There were also a number of family studies that suggested that there was some overlap between genetic factors in schizophrenia and psychotic affective disorder.

During the 1990s, an increasing number of critics questioned the validity of the Kraepelinian paradigm. These critics gathered a significant level of support, and many psychiatrists were prepared to acknowledge some of the issues. Yet, despite the acknowledgement of many clinicians that there are serious, if not fundamental, flaws to the Kraepelinian dichotomy, this classificatory distinction has not been formally abandoned. By the end of the 1990s it was generally accepted that psychotic symptoms occur, and that psychiatrists and psychologists needed new ways to delineate these symptoms, but no viable alternative paradigm for psychosis emerged by the end of the twentieth century. In 1988, Berrios and Hauser concluded that 'psychiatry still lives in a Kraepelinian world and its practitioners cannot escape the blinding embrace of its "episteme"' (Berrios and Hauser, 1988: 813). At the turn of the century, this was still the case.

\section{Acknowledgements}

This article is partly based on my dissertation for the MSc in History of Science, Technology and Medicine (2004-2005) organized by Imperial College London, University College London and the Wellcome Centre for the History of Medicine for which I received Wellcome Trust Funding. I would like to thank Michael Neve for his encouragement and supervision. I also want to thank the Medical Research Council for my current $\mathrm{PhD}$ funding at the Institute of Psychiatry, King's College London. Finally, I would like to thank Edgar Jones, Simon Wessely and Robin Murray for their comments on the paper. 


\section{References}

Andreasen, N. C. (1985) The Broken Brain: The Biological Revolution in Psychiatry (New York: Harper \& Row).

Andreasen, N. C. (1997) The evolving concept of schizophrenia: from Kraepelin to the present and future. Schizophrenia Research, 28(2-3), 105-9.

Angst, J., Scharfetter, C. and Stassen, H. H. (1983) Classification of schizo-affective patients by multidimensional scaling and cluster analysis. Psychiatria Clinica, 16, 254-64.

APA (1952) Diagnostic and Statistical Manual of Mental Disorders, 1st edn (Washington, DC: American Psychiatric Association).

APA (1968) Diagnostic and Statistical Manual of Mental Disorders, 2nd edn (Washington, DC: American Psychiatric Association).

APA (1987) Diagnostic and Statistical Manual of Mental Disorders, 3rd edn - Revised (Washington, DC: American Psychiatric Association).

APA (1994) Diagnostic and Statistical Manual of Mental Disorders, 4th edn (Washington, DC: American Psychiatric Association).

Bentall, R. P. (ed.) (1990) Reconstructing Schizophrenia (London: Routledge).

Bentall, R. [P.] (2003) Madness Explained: Psychosis and Human Nature (London: Allen Lane).

Bentall, R. P., Jackson, H. F. and Pilgrim, D. (1988a) Abandoning the concept of 'schizophrenia': some implications of validity arguments for psychological research into psychotic phenomena. British fournal of Clinical Psychology, 27(4), 303-24.

Bentall, R. P., Jackson, H. F. and Pilgrim, D. (1988b) The concept of schizophrenia is dead: long live the concept of schizophrenia? British fournal of Clinical Psychology, 27(4), 329-31.

Berrios, G. and Hauser, R. (1988) The early development of Kraepelin's ideas on classification: a conceptual history. Psychological Medicine, 18(4), 813-21.

Berrios, G. E., Luque, R. and Villagran, J. M. (2003) Schizophrenia: a conceptual history. International fournal of Psychology \& Psychological Therapy, 3(2), 111-40.

Blashfield, R. K. (1982) Feighner et al., invisible colleges, and the Matthew effect. Schizophrenia Bulletin, 8(1), 1-12.

Blashfield, R. K. (1984) The Classification of Psychopathology: Neo-Kraepelinian and Quantitative Approaches (New York: Plenum Press).

Bleuler, E. (1950) Dementia Praecox or the Group of Schizophrenias Translated by J. Zenkin (New York: International Universities Press); originally published in 1911 as Dementia Praecox oder die Gruppe der Schizophrenien.

Boyle, M. (1990) Schizophrenia: A Scientific Delusion? (London: Routledge).

Brockington, I. (1986) Diagnosis of schizophrenia and schizoaffective psychoses. In S. R. Hirsch and P. B. Bradley (eds), Pharmacology and Drug Treatment in Schizophrenia (Oxford: Oxford University Press), 166-200.

Ciompi, L. (1984) Is there really a schizophrenia? The long-term course of psychotic phenomena. British fournal of Psychiatry, 145, 636-40.

Cloninger, C. R. (1994) Pro: tests of alternative models of the relationship of schizophrenic and affective psychoses. In E. S. Gershon and C. R. Cloninger (eds), Genetic Approaches to Mental Disorders (Washington, DC: American Psychiatric Press), 149-62.

Cloninger, C. R., Martin, R. L., Guze, S. B. and Clayton, P. J. (1985) Diagnosis and prognosis in schizophrenia. Archives of General Psychiatry, 42(1), 15-25.

Compton, W. M. and Guze, S. B. (1995) The neo-Kraepelinian revolution in psychiatric diagnosis. European Archives of Psychiatry and Clinical Neuroscience, 245(4-5), 196-201. 
Costello, C. G. (1993a) Advantages of the symptoms approach to schizophrenia. In C. G. Costello (ed.), Symptoms of Schizophrenia (New York: John Wiley \& Sons), 1-26.

Costello, C. G. (1993b) From symptoms of schizophrenia to syndromes of schizophrenia. In C. G. Costello (ed.), Symptoms of Schizophrenia (New York: John Wiley \& Sons), 291-303.

Craddock, N. and Owen, M. J. (2005) The beginning of the end for the Kraepelinian dichotomy. British Fournal of Psychiatry, 186(5), 364-6.

Crow, T. J. (1986) The continuum of psychosis and its implication for the structure of the gene. British fournal of Psychiatry, 149, 419-29.

Crow, T. J. (1990) The continuum of psychosis and its genetic origins. The sixty-fifth Maudsley lecture. British Fournal of Psychiatry, 156, 788-97.

Crow, T. J. (1991) The failure of the Kraepelinian binary concept and the search for the psychosis gene. In A. Kerr and H. McClelland (eds), Concepts of Mental Illness: A Continuing Debate (London: Gaskell), 31-47.

Dalby, J. T., Morgan, D. and Lee, M. L. (1986) Schizophrenia and mania in identical twin brothers. Fournal of Nervous and Mental Disease, 174(5), 304-8.

Farmer, A. E., McGuffin, P. and Gottesman, I. I. (1987) Twin concordance for DSM-III schizophrenia: scrutinizing the validity of the definition. Archives of General Psychiatry, 44(7), 634-41.

Feighner, J. P., Robins, E., Guze, S. B., Woodruff, R. A., Winokur, G. and Munoz, R. (1972) Diagnostic criteria for use in psychiatric research. Archives of General Psychiatry, $26,57-62$.

Freeman, H. (2003) Madness explained: psychosis and human nature. Times Literary Supplement, (5246), 32.

Gershon, E. S., DeLisi, L. E., Hamovit, J., Nurnberger, J. I., Jr., Maxwell, M. E., Schreiber, J., et al. (1988) A controlled family study of chronic psychoses. Schizophrenia and schizoaffective disorder. Archives of General Psychiatry, 45(4), 328-36.

Gershon, E. S. and Rieder, R. O. (1980) Are mania and schizophrenia genetically distinct? In R. H. Belmaker and H. M. van Praag (eds), Mania, an Evolving Concept (New York: Spectrum), 97-109.

Ghaemi, S. N. (2003) The Concepts of Psychiatry: A Pluralistic Approach to the Mind and Mental Illness (Baltimore: John Hopkins University Press).

Goldstein, W. N. (1983) DSM-III and the diagnosis of schizophrenia. American fournal of Psychotherapy, 37(2), 168-81.

Gottesman, I. I. and Shields, J. (1982) Schizophrenia: The Epigenetic Puzzle (Cambridge: Cambridge University Press).

Gueguen, J. P. (1997) History of the concept of schizophrenia [1988]. In J. T. Dalby (ed.), Mental Disease in History: A Selection of Translated Readings, translated by K. Dalby, I. Moreira and N. Johnson (London: Peter Lang), 1-8.

Ion, R. and Beer, M. (2002) The British reaction to dementia praecox. 1893-1913. Part 1. History of Psychiatry, 13(3), 285-304.

Jablensky, A. (1995) Kraepelin's legacy: paradigm or pitfall for modern psychiatry? European Archives of Psychiatry and Clinical Neurosciences, 245(4-5), 186-8.

Kendell, R. E. (1987) Diagnosis and classification of functional psychoses. British Medical Bulletin, 43(3), 499-513.

Kendell, R. E. (1991) The major functional psychoses: are they independent entities or part of a continuum? Philosophical and conceptual issues underlying the debate. In A. Kerr and H. McClelland (eds), Concepts of Mental Disorder: A Continuing Debate (London: Gaskell), 1-16. 
Kendell, R. E. and Brockington, I. F. (1980) The identification of disease entities and the relationship between schizophrenic and affective psychoses. British fournal of Psychiatry, 137, 324-31.

Kendler, K. S., Gruenberg, A. M. and Tsuang, M. T. (1985) Psychiatric illness in first-degree relatives of schizophrenic and surgical control patients: a family study using DSM-III criteria. Archives of General Psychiatry, 42(8), 770-9.

Kety, S. S. (1985) The concept of schizophrenia. In M. Alpert (ed.), Controversies in Schizophrenia: Changes and Constancies: Proceedings of the 74th Annual Meeting of the American Psychopathological Association, New York City, March 1-3, 1984 (New York: Guilford Press), 3-11.

Klerman, G. L. (1978) The evolution of a scientific nosology. In J. C. Shershow (ed.), Schizophrenia: Science and Practice (Cambridge, MA: Harvard University Press).

Kraepelin, E. (1883) Compendium der Psychiatrie zum Gebrauche für Studierende und Aerzte (Leipzig: Abel Verlag).

Kraepelin, E. (1902) Clinical Psychiatry: A Text-Book for Students and Physicians, translated and edited by A. R. Diefendorf (New York and London: Macmillan); originally published in 1899 as Psychiatrie, 6th edn.

Kraepelin, E. (1919) Dementia Praecox and Paraphrenia; translated by R. M. Barclay, edited by G. M. Robertson (reprinted, New York: Robert E. Krieger, 1971); originally published in 1913 as Psychiatrie (8th edn), Band III, Teil II, Kapitel IX.

Kraepelin, E. and Lange, J. (1927) Psychiatrie, 9th edn, Vol. I (Leipzig: J. A. Barth).

Kraepelin, E. (1992) 'The manifestations of insanity' by Emil Kraepelin [1920], translated by D. Beer (Classic Text No. 12). History of Psychiatry, 3, 509-29.

Kuhn, T. S. (1962) The Structure of Scientific Revolutions (Chicago: University of Chicago Press).

Laing, R. D. (1960) The Divided Self: A Study of Sanity and Madness (London: Tavistock Publications).

Loranger, A. W. (1981) Genetic independence of manic-depression and schizophrenia. Acta Psychiatrica Scandinavica, 63(5), 444-52.

Maxmen, G. (1985) The New Psychiatrists (New York: New American Library).

McCarthy, L. P. and Gerring, J. P. (1994) Revising psychiatry's charter document: DSM-IV. Written Communication, 11(2), 147-92.

McGuffin, P., Reveley, A. and Holland, A. (1982) Identical triplets: non-identical psychosis? British fournal of Psychiatry, 140, 1-6.

Murray, R. M. and Foerster, A. (1987) Schizophrenia: is the concept disintegrating? fournal of Psychopharmacology, 1(3), 133-9.

Murray, R. M. and O'Callaghan, E. (1991) The congenital and the adult-onset psychoses: Kraepelin lost, Kraepelin found. In A. Kerr and H. McClelland (eds), Concepts of Mental Disorder: A Continuing Debate (London: Gaskell), 48-65.

Murray, R. M., O’Callaghan, E., Castle, D. J. and Lewis, S. W. (1992) A neurodevelopmental approach to the classification of schizophrenia. Schizophrenia Bulletin, 18(2), 319-32.

Ovsiew, F. (2000) An end to Kraepelinian nosology? fournal of Neuropsychiatry and Clinical Neurosciences, 12(3), 297-9.

Reich, T., Cloninger, C. R., Suarez, B. and Rice, J. (1982) Genetics of the affective psychoses. In L. Wing and J. K. Wing (eds), Handbook of Psychiatry, Vol 3. Psychoses of Uncertain Aetiology (Cambridge: Cambridge University Press), 147-59.

Rosenhan, D. (1973) On being sane in insane places. Science, 179(Jan.), 250-8.

Sarbin, T. R. (1990) Toward the obsolescence of the schizophrenia hypothesis. Fournal of Mind and Behaviour, 11(3-4), 259-83. 
Spitzer, R. L. and Fleiss, J. L. (1974) A reanalysis of the reliability of psychiatric diagnosis. British fournal of Psychiatry, 125, 341-7.

Spitzer, R. L. and Williams, J. B. W. (1987) Introduction. In APA, Diagnostic and Statistical Manual (3rd Edn-Revised) (Washington DC: American Psychiatric Association), xvii-xxvii.

Stassen, H. H., Scharfetter, C., Winokur, G. and Angst, J. (1988) Familial syndrome patterns in schizophrenia, schizoaffective disorder, mania, and depression. European Archives of Psychiatry and Neurological Sciences, 237(2), 115-23.

Szasz, T. S. (1974) The Myth of Mental Illness: Foundations of a Theory of Personal Conduct (rev. edn) (New York: Harper and Row).

Van Bakel, A. H. A. C. (1993) Emil Kraeplin and Wundtian experimental psychology. In L. de Goei and J. Vijselaar (eds), First European Congress on the History of Psychiatry and Mental Health Care (Rotterdam: Erasmus Publishing), 115-24.

Van Os, J., Gilvarry, C., Bale, R., Van Horn, E., Tattan, T., White, I. and Murray, R. (1999) A comparison of the utility of dimensional and categorical representations of psychosis. UK700 Group. Psychological Medicine, 29(3), 595-606.

Van Os, J., Jones, P., Sham, P., Bebbington, P. and Murray, R. M. (1998) Risk factors for onset and persistence of psychosis. Social Psychiatry and Psychiatric Epidemiology, 33(12), 596-605.

Venables, P. H. (1990) Longitudinal research on schizophrenia. In R. Bentall (ed.), Reconstructing Schizophrenia (London: Routledge), 184-207.

Wildenauer, D. B., Schwab, S. G., Maier, W. and Detera-Wadleigh, S. D. (1999) Do schizophrenia and affective disorder share susceptibility genes? Schizophrenia Research, 39(2), 107-11, and 160 (discussion). 